\title{
Canadian Asthma Consensus Conference Summary of recommendations
}

\author{
PIERRE ERNST MD MSc FRCPC, CHAIR, ASTHMA COMMITTEE, CANADIAN THORACIC SOCIETY \\ J MARK FITZGERALD MB FRCPC, CHAIR, ADULT WORKING GROUP \\ SHELDON SPIER MD FRCPC, CHAIR, PEDIATRIC \\ WORKING GROUP \\ TABLE 1 \\ Levels of evidence
}

Level 1 Evidence from one or more randomized clinical trials

Level 2 Evidence from one or more well-designed cohort or case-control studies

PREAMBLE

The Asthma Committee of the Canadian Thoracic Society invited a group of Canadian physicians with a particular interest in asthma to meet in Montebello, Quebec, March 9-12, 1995 to arrive at a consensus statement on the optimal approach to the management of asthma in the pediatric and adult ambulatory care settings. The societies and associations represented are listed in the appendix with the names of the contributors to this document.

The objectives of the Montebello conference were:

1. To review the current ambulatory care management of asthma in Canada;

2. To develop guidelines with the participation of family physicians and specialists;

3. To develop guidelines which are evidence-based;

4. In creating evidence-based guidelines to focus attention on aspects of asthma management that are currently not supported by randomized controlled trials;

5. To develop strategies that allow for the implementation of rational guidelines at a local level.

Recommendations were based on a critical review of the scientific literature by small groups prior to the meeting and are categorized according to the strength of the scientific evidence supporting each recommendation (Table 1).

Level 3 Consensus from expert groups based on clinical experience

Evidence was further subdivided into a number of categories as follows:

A. Good evidence to support a recommendation for use

B. Moderate evidence to support a recommendation

C. Poor evidence to support a recommendation for or against use

D. Moderate evidence to support a recommendation against use

E. Good evidence to support a recommendation against use

\section{DEFINITION AND PATHOGENESIS OF ASTHMA}

The workshop adopted the following working definition of asthma: Asthma is a disorder of the airways characterized by paroxysmal or persistent symptoms (dyspnea, chest tightness, wheeze and cough), with variable airflow limitation and airway hyperresponsiveness to a variety of stimuli.

We believe airway inflammation (including mast cells and eosinophils) or its consequences is important in the pathogenesis and persistence of asthma. This provides a strong argument for the recommendation that the management of asthma should focus on the reduction of this inflammatory state through environmental control measures and the early use of disease-modifying agents, rather than symptomatic therapy alone. 


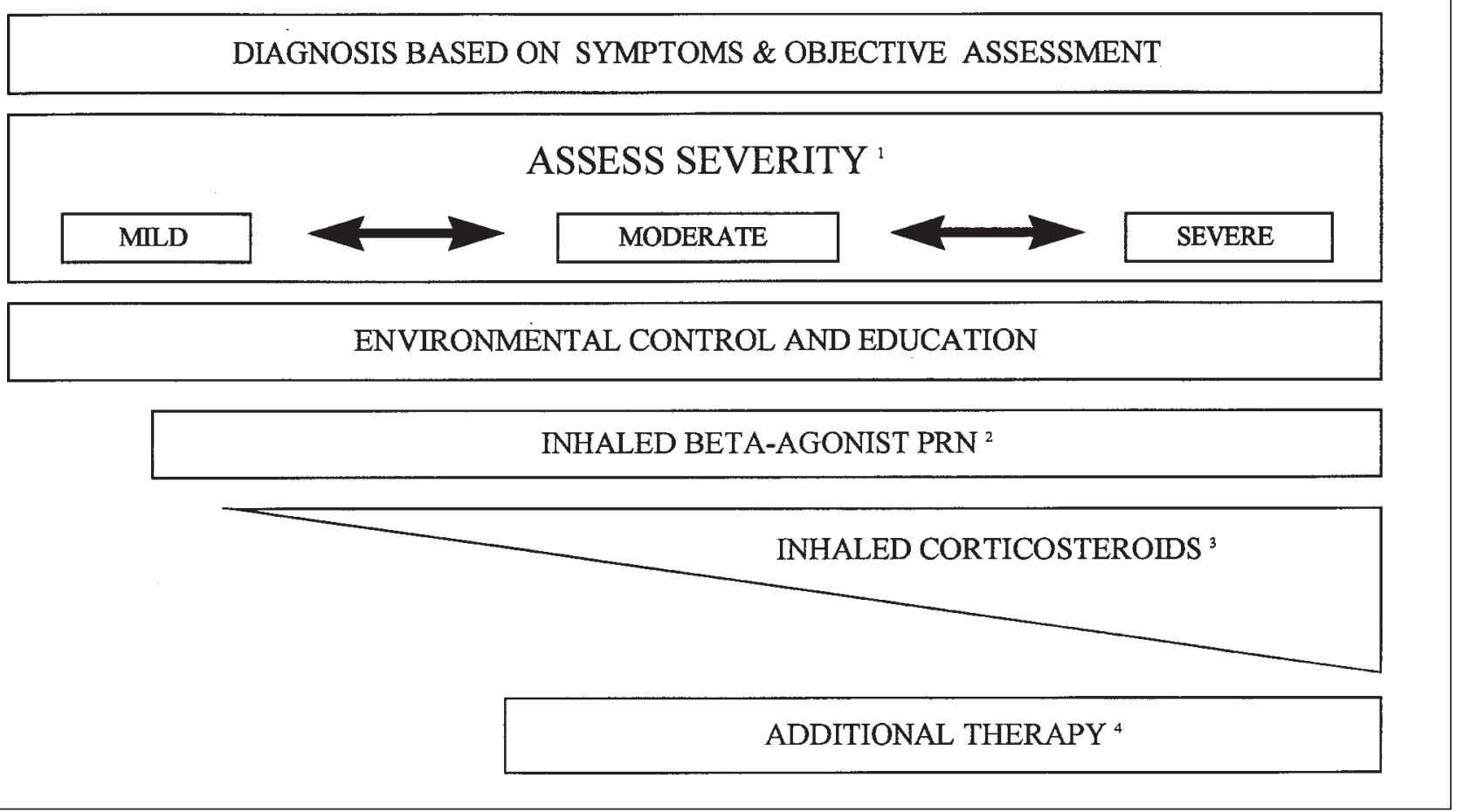

Figure 1) Asthma continuum. 1. The severity of asthma in an individual patient is judged by the frequency and chronicity of symptoms, the presence of persistent airflow limitation and the medication required to maintain control. Signs of severe asthma include previous near-fatal episode (loss of consciousness, intubation), recent hospitalization or emergency room visit, night-time symptoms, limitation of daily activities, need for beta $2_{2}$-agonist several times per day or at night, forced expiratory volume in $1 \mathrm{~s}\left(F E V_{1}\right)$ or peak expiratory flow (PEF) less than $60 \%$ predicted. 2. Beta ${ }_{2}$-agonist should not be required daily; if used more than three times per week, institute anti-inflammatory or preventive therapy. 3. The usual initial dose of inhaled corticosteroid is 400 to $1000 \mu \mathrm{g} /$ day of beclomethasone, budesonide or the equivalent. Initial dose in children may be lower, ie, beclomethasone 200 to $800 \mu \mathrm{g}$ or equivalent. If asthma is mild or if control is achieved with beclomethasone less than $400 \mu \mathrm{g}$ or equivalent, a trial of cromolyn (children) or nedocromil may be warranted. 4 . Long-acting beta2-agonists are an additional therapy for patients with unsatisfactory symptom control despite an optimal dose of inhaled steroids, particularly when there are nocturnal symptoms. In subjects who remain symptomatic despite high doses of inhaled corticosteroid therapy, theophylline improves symptoms and lung function

\section{THE MANAGEMENT OF ASTHMA}

General principles: The participants felt that the stepped care approach advocated in previous guidelines may have been counter-productive by promoting an overly rigorous stratification of levels of asthma care. The concept of the asthma continuиm was therefore adopted to reflect a more dynamic therapeutic approach, which allows drug therapy to be adapted to the severity of the underlying illness while facilitating adjusting the intensity of therapy to the degree of control (see below) achieved at any one time. This concept is outlined in Figure 1.

The severity of asthma in an individual patient is judged by the frequency and chronicity of symptoms, the presence of persistent airflow limitation and the medication required to maintain control. In all but those patients with mild or intermittent disease, asthma severity can best be evaluated after an aggressive trial of therapy with inhaled corticosteroids (minimum of beclomethasone $200 \mathrm{~g}$ or the equivalent in children and $400 \mathrm{~g}$ minimum in adolescents and adults) or a course of oral corticosteroids in more troublesome cases. Signs of severe or poorly controlled asthma include the occurrence of a prior near-fatal episode (loss of consciousness, intubation), recent hospitalization or emergency room visit, night time symptoms, limitation of daily activities, need for inhaled beta2-agonist several times per day or at night, and forced expiratory volume in $1 \mathrm{~s}\left(\mathrm{FEV}_{1}\right)$ or peak expiratory flow (PEF) less than $60 \%$ predicted. Furthermore, asthma severity is likely to vary over time; this is of special importance in children in whom asthma often improves with age, suggesting the need to attempt a reduction in medication when asthma ceases to be troublesome.

Diagnosis: Objective measurements are needed to confirm the diagnosis of asthma and to assess asthma severity. The diagnosis of asthma should be confirmed objectively in all but the most trivially symptomatic subjects [Level 3A]. Objective documentation of variable airflow obstruction can be obtained by one or more of the following means.

\section{Recommendations:}

i) $\mathbf{F E V}_{1}$ : variable airflow obstruction can be documented by spontaneous variability in $\mathrm{FEV}_{1}$ or by improvement 15 mins after inhaled beta2-agonist administration. (The term beta2-agonist refers to short-acting inhaled agents throughout this document unless stated otherwise.) A $12 \%$ or greater improvement in $\mathrm{FEV}_{1}$ (at least $180 \mathrm{~mL}$ ) 
after beta2-agonist administration is considered significant [Level 1A]. Changes in $\mathrm{FEV}_{1}$ that occur over time, without any specific therapeutic intervention or after a prolonged course of oral (more than one week) or inhaled corticosteroids (more than two weeks), should demonstrate an increase of at least $20 \%$ (minimum 250 $\mathrm{mL}$ ) [Level 2A].

ii) PEF: home measurement of PEF, incorporating response to inhaled beta2-agonist, may be used to document variable airflow obstruction. A mean percentage difference between the highest and lowest of four PEF values (AM and PM pre- and post-bronchodilator on the same day) of $20 \%$ or more over a period of several weeks is indicative of asthma [Level 2A]. With less reliability, a $20 \%$ or greater improvement in PEF 15 mins after the administration of 200 to $400 \mathrm{~g}$ inhaled salbutamol or the equivalent may be used as an indicator of asthma in the physician's office when spirometry is not available [Level 3B].

iii) Airway hyperresponsiveness: in subjects with a normal FEV 1 , excessive bronchoconstrictor responsiveness can be documented by finding hyperresponsiveness to histamine or methacholine. The test is usually only available in specialized centres and this may limit its utility to the primary care physician. Assessment of bronchial hyperresponsiveness may be useful in subjects who, despite normal airway calibre, require excessive medication for symptom control or fail to respond to therapy [Level 3A]. Such an objective measure of airway responsiveness may help the physician to correlate symptoms with the degree of airway hyperresponsiveness or to verify the diagnosis or etiology of the patient's symptoms.

Special considerations in children: Pharmacological reversibility of airway obstruction as a method of diagnosing asthma is controversial when dealing with infants and toddlers, though less so among those with recurrent wheezing. Furthermore, the relationship between asthma and airway hyperresponsiveness in preschool children is less straightforward than in older subjects. In addition, wheezing disorders are very common in infancy and for the majority of children; this will disappear with age without residual 'asthma'.

In children who cannot perform reliable pulmonary function tests (most commonly spirometry), consensus was that the likelihood of asthma increases with the presence of an increasing number of the following features: wheezing occurring after the age of one year, accompanied by attacks of dyspnea, or more than three times per year (especially if not related to a viral illness); severe episodes of dyspnea and wheezing; prolonged cough, most notably occurring with physical activity or disturbing sleep; evidence of atopic diathesis in the child or his or her direct family; symptomatic or objective evidence of improvement with asthma therapy; and parental smoking [Level 3B].

Allergy assessment: Allergens are recognized as impor-
TABLE 2

Criteria for asthma control

\begin{tabular}{|c|c|c|}
\hline Parameters & Good control & Acceptable control \\
\hline Daytime symptoms & None & $<3$ days/week \\
\hline Night-time symptoms & Not woken & $<1$ night/week \\
\hline Physical activity & Normal & Normal \\
\hline Exacerbations & None & Mild, infrequent \\
\hline Absenteeism & None & None \\
\hline $\begin{array}{l}\text { Need for prn } \\
\text { beta2-agonist }\end{array}$ & None $^{*}$ & $<3$ doses/week \\
\hline $\mathrm{FEV}_{1} ; \mathrm{FEV}_{1} / \mathrm{FVC}$ & Normal & $90 \%$ personal best \\
\hline PEF & Normal & $90 \%$ personal best \\
\hline PEF variability & $\begin{array}{l}<10 \% \text { diurnal } \\
\text { variation }^{\dagger} \\
5 \text { days/week }\end{array}$ & $\begin{array}{l}<15 \% \text { diurnal } \\
\text { variation } \\
5 \text { days/week }\end{array}$ \\
\hline
\end{tabular}

FEV ${ }_{1}$ Forced expiratory volume in $1 \mathrm{~s}$; FVC Forced vital capacity obtained by spirometry; PEF Peak expiratory flow obtained with a portable peak flow meter. "May use one dose per day for prevention of exercise-induced symptoms; ${ }^{\dagger}$ Diurnal variation is calculated as the highest minus the lowest divided by the highest PEF multiplied by 100

tant inducers of acute exacerbations of asthma and contribute significantly to the initiation and persistence of airway inflammation:

\section{Recommendations:}

i) Allergy assessment is warranted in most asthmatics [Level 3A].

ii) Skin or radioallergosorbent tests provide useful and reliable assessment of environmental allergies [Level $1 \mathrm{~A}]$.

iii) Allergy testing must be interpreted in light of the history provided by the patient [Level 3A].

Special considerations in children: Above age five years, similar skin test reagents, namely aeroallergens, are indicated. In younger children, indoor allergens, specifically mites, furred pets and, under certain conditions, cockroaches are likely to be most important [Level 2A]. While allergy skin testing may be negative under the age of two years, even when common environmental allergens are of etiological relevance, it may be indicated in selected instances [Level 3C].

Criteria for control of asthma: One of the primary goals of therapy is to obtain the best results possible in an individual patient based on the fewest symptoms, least interference with daily living, least need for bronchodilators, best FEV 1 or PEF, in particular on waking, with the least variability and fewest side effects from medications [Level 3A]. Identifying best results often requires an aggressive trial of therapy, possibly including a course of oral prednisone.

Based upon the concept of the asthma continuum, once best results have been defined and achieved in the individual patient, medication should be reduced to the lowest possible dose with the aim to remain within the parameters of control outlined in Table 2 (see also Figure 2). A corollary is that there may be loss of control of asthma, and both patient and 


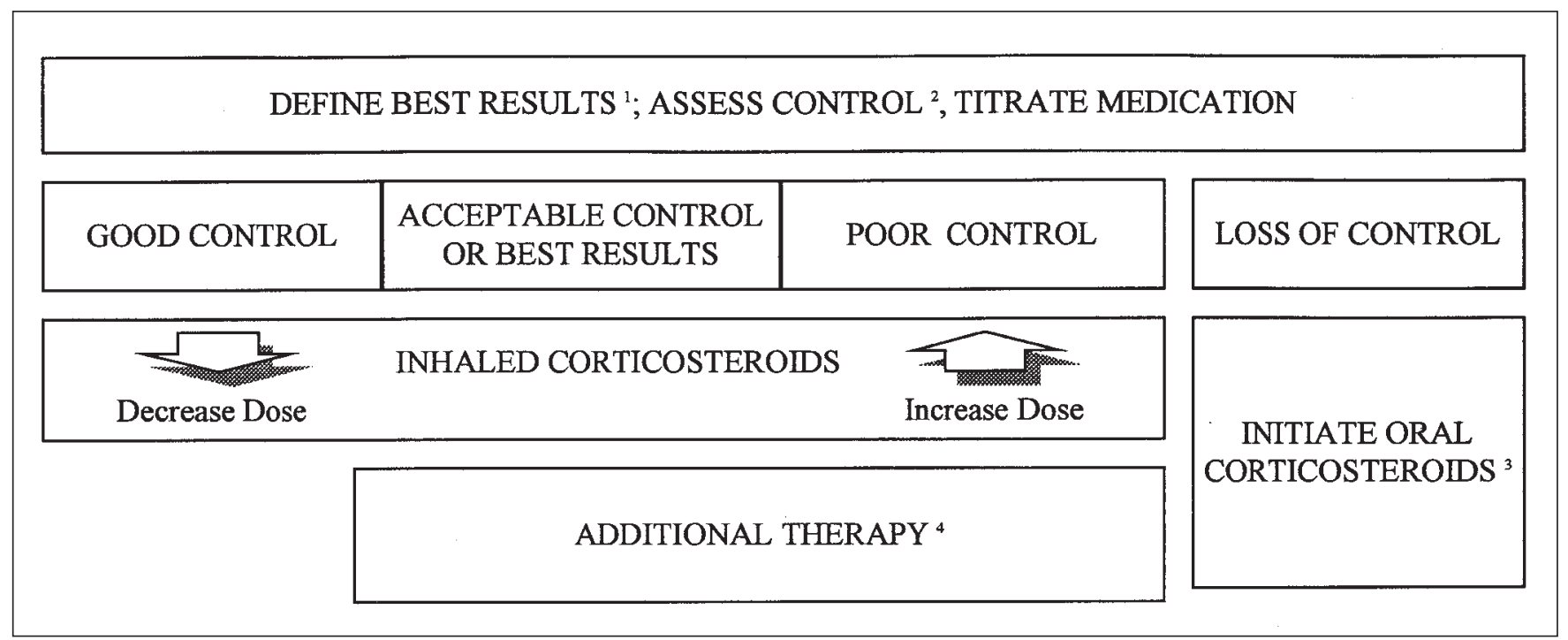

Figure 2) Assessment of control. 1. Best results are defined as a minimum of symptoms, ability to carry out all normal activity, absence of need for bronchodilators, maximal attainable forced expiratory volume in $1 \mathrm{~s}\left(F E V_{1}\right)$ or peak expiratory flow (PEF), and no or minimal side effects from medication. 2. Criteria for control are listed in Table 2. 3. In some cases, when loss of control is neither severe or of long duration, a doubling of the dose of inhaled corticosteroid may be attempted in lieu of oral corticosteroids. 4. Strong consideration should be given to removing additional therapy before decreasing the dose of inhaled corticosteroid

physician should be proactive in responding to this. The general principles on which this response should be based are as follows:

i) Loss of control should elicit an increase in therapy as early as possible so as to minimize the occurrence and severity of asthma exacerbations (defined as an episode of loss of control of asthma requiring an unscheduled physician or emergency department visit) and to reverse these rapidly [Level 3A].

ii) Treatment of an exacerbation will depend upon the severity of the episode and nature of the maintenance therapy; corticosteroids at increased doses, either oral or inhaled, will be required [Level 1A].

Patient monitoring: Home monitoring of asthma is a useful tool to determine whether control of asthma is adequate and whether therapy needs to be adjusted. Loss of control is most easily identified by an increase in asthma symptoms and must be relied upon in children under the age of six years. However, persistent airflow limitation is frequently present even in patients who deny or fail to report symptoms. Furthermore, physical examination is notoriously inaccurate in assessing the severity of airflow obstruction. Objective measures of lung function are thus required for the optimal assessment of asthma in the office; spirometry is more accurate and reliable than PEF. Serial measures of PEF are more informative than single measures and can be used to follow patients in their usual environment. The patient (or parents) needs to be provided with instructions as to what steps must be taken if worsening of symptoms or deterioration in home measurements of PEF occur (action plan).

\section{Recommendations:}

i) PEF measurements at home are useful in adult patients who are poor perceivers of airway obstruction or who have severe asthma [Level 2A].

ii) Monitoring of symptoms and PEF should be linked to an appropriate action plan [Level 2A].

iii) Enquiry about symptoms and beta2-agonist use, including their pattern (especially nocturnal) and frequency, should take place at every visit [Level 3A].

iv) Adequacy of use of the inhalation device should be directly assessed [Level 2A].

v) Assessment of asthma should include measurement of airway calibre $\left(\mathrm{FEV}_{1} / \mathrm{FVC}\right.$ or PEF) [Level $\left.3 \mathrm{~A}\right]$.

vi) Longitudinal follow-up of airway responsiveness is not generally recommended to monitor response to treatment [Level 3D].

\section{ENVIRONMENTAL ISSUES}

Improving the quality of the asthmatic's environment is of paramount importance for a safe and effective approach to management [Level 2A].

Respiratory irritants: These are encountered both indoors and outdoors. Air pollution is the principal outdoor irritant and the constituents linked to exacerbations of asthma are, in order of importance, respirable particulates, ground-level ozone and sulphur dioxide. Indoor irritants, especially second-hand tobacco smoke, appear to represent an even greater hazard to the health of the asthmatic in the context of the Canadian climate. Among other indoor irritants, the strongest evidence for an etiological role in asthma is available for the oxides of nitrogen. Various types of indoor air cleaners are available and, while several have been shown to reduce levels of irritants significantly, health benefits have yet to be consistently demonstrated. 


\section{Recommendations:}

i) Exposure to environmental tobacco smoke should be avoided. Parents or caregivers of asthmatic children especially should be encouraged not to smoke [Level $2 \mathrm{~A}]$.

ii) During periods of poor air quality, asthmatics should attempt to minimize their levels of outdoor activity [Level 2A].

iii) Although some of the effects of exposure to irritants can be prevented or reversed with bronchodilator inhalation, drug therapy should not be used as a substitute for avoidance of exposure [Level 3D].

iv) There is insufficient information to recommend the use of residential air cleaners [Level 3C].

Aero-allergens: Allergen exposure plays a pivotal role in the development and exacerbation of asthma among atopic subjects, ie, in the majority of asthmatics. Exposure to aeroallergens at an early age may be especially important for the development of asthma that persists into later childhood. The indoor allergens derived from furred pets, especially cats, and dust mites contribute most to asthma morbidity. Indoor and outdoor exposure to moulds may also be of significance. Minimizing excess humidity indoors is a simple way of reducing contamination by dust mites and indoor moulds.

\section{Recommendations:}

i) There is a clear need to identify allergens to which a subject has become sensitized and to institute a systematic program to eliminate or, at least, substantially reduce such exposures [Level 1A].

ii) Dust mite control measures are effective in improving asthma among patients sensitized to these allergens [Level 1B].

iii) The reduction of exposure to cat allergen cannot be achieved without removing the pet from the home [Level 2B].

iv) Humidity in the home, including the asthmatic's bedroom, should be kept below 50\% [Level 2A].

Occupational asthma: Asthma may be related to work by several means:

1. Exposure to irritants such as fumes, vapours or dusts may trigger bronchospasm in subjects with pre-existing asthma;

2. Single acute exposure to high levels of an irritant vapour, fume or smoke has been associated with the development of asthma in previously normal subjects. This condition is called reactive airways dysfunction syndrome (RADS);

3. Finally, occupational asthma $(\mathrm{OA})$ is the most frequent occupational pulmonary disease and is defined as asthma that is induced by exposure to a specific sensitizing agent found in the work place (excluding irritant induced bronchospasm). The importance of identifying subjects with OA lies in the fact that progressive deterioration and even permanent disability may occur if exposure is continued after the onset of symptoms. Conversely, early withdrawal may be associated with disappearance of symptoms and airway hyperresponsiveness. It is important to note that the presence of asthma before encountering an occupational exposure to a sensitizing agent does not preclude the development of true OA.

\section{Recommendations:}

i) Asthmatics should not be exposed to irritant levels higher than the threshold limit value (the airborne concentration to which nearly all workers may be exposed repeatedly without ill effects), although even this limit may not be safe in subjects with severe airway hyperresponsiveness [Level 3B].

ii) An occupational history is warranted in all adults with asthma [Level 3A].

iii) The diagnosis of true OA secondary to exposure to a sensitizing substance at work needs to be objectively established. The gold standard for diagnosis is a specific inhalation challenge in the laboratory or workplace [Level 2B].

Viral infections - role in asthma: Intermittent episodes of cough and wheezing are often associated with viral and sometimes mycoplasma infections in children. Lung function and airway responsiveness may be adversely affected for weeks after such infections. Respiratory syncytial virus (RSV), in particular, is associated with bronchitis in infancy and with recurrent bouts of wheezing. It is not clear whether RSV ' $\mathrm{i}$ nduces' asthma or selects predisposed infants, or both. There is evidence to support both points of view. Recurrent viral induced wheezing is thought to decrease in frequency and severity with time. The degree of personal or family atopy helps predict the likelihood that wheezing will be persistent.

\section{DRUG THERAPY OF ASTHMA}

As illustrated in Figure 2, an inhaled corticosteroid is the single best agent for bringing and keeping asthma under control [Level 1A]. As well, inhaled corticosteroids may improve the prognosis of this condition over the long term [Level 2A]. Issues of long term safety, especially with the use of high doses of inhaled corticosteroids in children, must be considered. For this reason, some participants felt that in children with mild asthma, a trial of inhaled cromoglycate could be given or could be substituted for low dose inhaled corticosteroids once adequate control of asthma is achieved. Among infants, a similar role to cromoglycate was suggested for ketotifen.

Most important, the pathophysiology of asthma consists of inflammation and smooth muscle spasm localized to the airways. For this reason, and in order to limit untoward effects of drug therapy, the inhaled route of delivery of medications is preferred in most situations.

\section{Recommendations for therapy with corticosteroids:}


i) In adults and older children, the initial recommended dose of inhaled corticosteroids for mild to moderate asthma is in the range of 400 to $1000 \mathrm{~g}$ daily of beclomethasone or budesonide on a twice daily basis. Fluticasone has been shown to have a 2:1 potency ratio compared with beclomethasone. Higher or more frequent doses of inhaled or, on occasion, oral corticosteroids may be required if the asthma is more severe. Once best results are achieved, the dose should be reduced to identify the minimum required to maintain this state [Level 3A].

ii) In younger children without a recent emergency room visit, hospitalization or course of oral corticosteroids, and in whom symptoms are not too troublesome, an initial dose of inhaled corticosteroids equivalent to $200 \mathrm{~g}$ of beclomethasone a day is recommended [Level 3A]. In the stable state, there appears to be little advantage to more frequent than bid dosing [Level 2A].

iii) Exacerbations of asthma should be treated as early as possible to prevent them from becoming severe and in order to reverse them as quickly as possible [Level 3A]. The added dose of inhaled steroid required will depend both on the severity of the exacerbation and the intensity of maintenance therapy. For most exacerbations among patients taking the equivalent of inhaled beclomethasone $1500 \mathrm{~g}$ per day or less in whom the episode is not too severe (those able to carry out activities of daily living, using fewer than 12 puffs of short acting beta2-agonist per day providing at least $3 \mathrm{~h}$ of relief, and $\mathrm{FEV}_{1}$ or PEF $60 \%$ or more of baseline), the dose of inhaled corticosteroids can be increased two-to fourfold (taken qid) [Level 3B]. The dose of inhaled steroid should be reduced to the usual maintenance dose over a period of several weeks once best results are again observed.

iv) If the attack is more severe, ie, $\mathrm{FEV}_{1}$ or PEF below $60 \%$ of best or the response to an increased dose of inhaled corticosteroids is inadequate, a course of oral prednisone $(0.5$ to $1 \mathrm{mg} / \mathrm{kg} / \mathrm{day})$ is usually required and should last a full two weeks in adults. In children, one week of oral corticosteroids may be sufficient. With maintenance inhaled corticosteroids, a gradual reduction in dose (taper) of the oral corticosteroid is not required if there have been four or fewer short courses of oral corticosteroids in the preceding year [Level 1A].

v) In infants, acute episodes of wheezing usually respond to oral prednisone $(1 \mathrm{mg} / \mathrm{kg} /$ day $)$ for two to seven days depending on the duration of symptoms [Level 1A].

vi) Over a period of several years, delay in the initiation of therapy with inhaled corticosteroids is associated with lower lung function [Level 2B].

Safety of inhaled corticosteroids: At doses up to 1000 $\mathrm{g} /$ day of beclomethasone or the equivalent in adults and $400 \mathrm{~g} /$ day in pre-adolescent children, the adverse effects of inhaled corticosteroids may constitute a nuisance but are very rarely associated with significant systemic effects. Corticosteroid induced skin thinning and bruising indicate chronic systemic steroid activity, but are generally not clinically important unless patients are receiving greater than the equivalent of $1000 \mathrm{~g}$ inhaled beclomethasone/day or repeated courses of oral corticosteroids. The total combined daily doses of oral and inhaled corticosteroids interact to increase the risk of hypothalamic-pituitary adrenal suppression. The additive effect of nasal corticosteroids may also have to be considered. Oral candidiasis and dysphonia are not uncommon local side effects of therapy in adults but are uncommon in children. Growth inhibition is of particular concern in children. The dose at which this may occur will vary according to individual susceptibility, the type of inhaled corticosteroids as well as the delivery device. Clinically significant effects on growth are distinctly unusual at doses less than the equivalent of $400 \mathrm{~g}$ daily of inhaled beclomethasone. Long term use of high doses of inhaled corticosteroids may increase the risk of osteoporosis in high-risk groups.

\section{Recommendations:}

i) The lowest dose of inhaled corticosteroids required to maintain good asthma control should be used [Level 1A].

ii) Among patients whose asthma is well controlled, a reduction in the dose of inhaled corticosteroids should be attempted in order to identify the lowest dose required to maintain control. Such an attempt at dose reduction should be on a regular basis [Level 2A].

iii) Local side effects should be minimized by careful mouth rinsing and gargling and by using a large-volume spacer device when the delivery device is a metered-dose inhaler [Level 1A].

iv) Referral to a specialist is recommended in adults when more than $1000 \mathrm{~g}$ of inhaled beclomethasone or its equivalent is required on an ongoing basis. In children, the threshold for referral to a specialist is lower [Level $3 \mathrm{~A}]$.

v) Inhaled corticosteroids should be continued during pregnancy but the use of the lowest dose consistent with achieving and maintaining optimal asthma control is recommended [Level 3A]. Inhalation of beclomethasone is not associated with the appearance of steroid in breast milk and, therefore, inhaled corticosteroids can be continued during lactation.

vi) Routine ophthalmologic surveillance for posterior subcapsular cataracts is not warranted in patients treated with inhaled corticosteroids [Level 2D]. Such an examination may be limited to subjects complaining of a change in visual acuity.

vii) An estrogen supplement should be provided in glucocorticoid-treated postmenopausal women, unless a positive contraindication is present [Level 2B].

viii) It is not necessary to monitor patients treated with inhaled steroid for possible adverse effects on serum glucose, electrolytes or lipid levels [Level 3A].

ix) Careful monitoring of patients taking greater than 
$2000 \mathrm{~g}$ inhaled corticosteroids is warranted to define better the long term effects on bone metabolism [Level 3B].

Anti-allergic agents: Inhaled cromoglycate and nedocromil appear to prevent some of the inflammatory effects that follow exposure to aero-allergens. They have an excellent safety profile but are much less effective than inhaled corticosteroids in controlling airway inflammation. In patients with mild or moderate chronic asthma, cromoglycate or nedocromil provide a modestly effective and extremely safe alternative to low doses of inhaled corticosteroids. There is no proven benefit obtained by adding cromoglycate to an established regimen containing corticosteroids, either inhaled or oral, while nedocromil's ability to facilitate small reductions in steroid dosage in adults with systemic steroid side effects is equivocal.

Ketotifen is an oral antihistamine for which there is evidence of benefit for mild asthma in children under the age of five years and whose route of administration is attractive in this age group.

All three agents have the disadvantage of requiring many weeks of therapy before a beneficial effect on persistent symptoms occurs. For cromoglycate and nedocromil, qid dosing is required, at least initially. None of these agents has any role in the treatment of acute exacerbations of asthma.

\section{Recommendations:}

i) A trial of one of these agents (ketotifen in infants and toddlers, cromoglycate in children and nedocromil in adolescents and adults) is warranted in asthma of mild to moderate severity, when toxicity or fear of toxicity from corticosteroids is a major concern [Level 1C].

ii) If symptoms persist, inhaled corticosteroids should be prescribed instead [Level 1A].

iii) Cromoglycate and nedocromil are effective in prevention of exercise induced bronchospasm, though not as effective as inhaled beta2-agonists [Level 1A].

Short-acting beta2-agonists: These remain the drugs of choice for the relief of acute symptoms due to bronchospasm. Agents available in Canada include salbutamol, fenoterol, terbutaline, metaproterenol, pirbuterol and procaterol. They are most useful as rescue medication to be taken on an asneeded basis. There is little concern regarding cardiac and other systemic effects of inhaled short-acting beta2-agonists. There is evidence that frequent use (on a regular qid basis) or high doses of beta2-agonists used for chronic maintenance therapy may cause long term decreased control of asthma and, possibly, increased morbidity and mortality.

\section{Recommendations:}

i) Short-acting beta2-agonists used infrequently (fewer than three times weekly, not including their use to prevent exercise-induced symptoms) are the drugs of choice for relief of asthma symptoms that break through maintenance therapy with other drugs [Level 1A].

ii) These agents are the most effective therapy for the prevention and relief of exercise induced bronchospasm [Level 1A].

iii) In children, and occasionally in adults, with very mild episodic symptoms and normal pulmonary function tests, intermittent use of an inhaled beta2-agonist alone may be adequate therapy [Level 3C].

iv) In most patients the use of these agents should be limited to rescue medication [Level 2B].

Long-acting beta2-agonists: Published guidelines and reviews have suggested that long-acting beta2-agonists (salmeterol and formoterol) can be used as an additional treatment in subjects whose asthma is not adequately controlled with inhaled corticosteroids. The optimal dose of inhaled steroids under which patients should be placed before considering adding an inhaled long-acting beta2-agonist is still undetermined.

\section{Recommendations:}

i) Long-acting beta2-agonists are an alternative additional therapy for patients with moderate asthma with unsatisfactory symptom control despite an optimal dose of inhaled steroids in adults, particularly when there are nocturnal symptoms [Level 1B]. Inhaled steroids should not be stopped [Level 3A].

ii) Before introducing long-acting beta2-agonists, adequate education should be provided to the patient on how to use the drug and what to do if asthma flares up (action plan); long-acting beta2-agonists are designed to protect against breakthrough symptoms; therefore, the threshold for action should be at lower levels of need for a short-acting beta2-agonist [Level 3A].

iii) Ideally, an information hand-out should be given to the patient on long-acting beta2-agonists and close follow-up to assure compliance with instructions is suggested [Level 3B].

iv) Concern regarding compliance, especially neglect of anti-inflammatory therapy and overuse of short-acting beta2-agonists, led the pediatric working group to recommend that this class of medication should be used with great caution in adolescents [Level 3D].

v) These medications should not be introduced when asthma is unstable [Level 3D].

vi) Long-acting beta2-agonists should never be used as a rescue medication [Level $1 \mathrm{E}]$.

Theophylline and its derivatives: Theophylline remains an effective anti-asthma drug for both children and adults. Advantages include oral administration, relatively low cost and availability of drug monitoring. Its dosing is complicated by numerous factors, including drug interaction, organ dysfunction, age and inter-individual variability. In addition, its use is associated with many potential side effects, most of which are dose related. Common side effects include gastric intolerance, irritability, headaches and insomnia. $\mathrm{Pa}-$ tients vary in susceptibility to side effects. Introduction of the 
drug in small increments often reduces the frequency of reported side effects.

Recent studies suggest a possible anti-inflammatory effect of theophylline present at lower serum levels than traditionally targeted. However, the clinical significance of this remains to be demonstrated.

\section{Recommendations:}

i) Theophyllines should not be used as first-line therapy in asthma [Level 1A].

ii) In subjects who remain symptomatic despite high doses of inhaled corticosteroid therapy, theophylline improves daytime and night-time symptoms and lung function [Level 1B], though this is less apparent in children [Level 1C]

iii) A therapeutic trial should be carefully undertaken to identify responders for whom the drug should be continued [Level 3B].

iv) When given to a naive patient, dose must be slowly titrated to minimize side effects. Ideally, serum levels should measured, especially if high doses are used [Level 3B].

Anticholinergics: Quaternary isopropyl derivatives of atropine are the most commonly used anticholinergic bronchodilators. Typically, ipratropium bromide or similar compounds act more gradually than beta2-agonists such as salbutamol, fenoterol or terbutaline. Inhaled quaternary anticholinergic bronchodilators offer modest bronchodilation in stable ambulatory asthma patients. These drugs may be of greater value in older patients and in those with a combination of both asthma and chronic obstructive pulmonary disease (COPD). There is little information concerning the use of these agents in the long term treatment of asthma in children. During acute exacerbations, these agents may provide additional bronchodilation to optimal doses of beta2-agonists in both adults and children.

\section{Recommendation:}

i) Inhaled anticholinergics are not first-line agents for the treatment of asthma, with the rare exception of patients who are unable to tolerate beta2-adrenergic bronchodilators [Level 3D].

Nonsteroidal immunosuppressive therapy: Fortunately, potent nonsteroidal immunosuppressant drugs taken systemically for asthma are rarely required for the treatment of asthma. In most instances, they are given in the presence of severe disease usually requiring high dose systemic corticosteroids to maintain control or where, even with such high doses, control is not being achieved or systemic corticosteroid side effects are unacceptable. Drugs in this category act widely with potentially serious side effects. These drugs should not be considered before therapy outlined elsewhere in this document has been carefully applied with particular attention to issues of compliance, environmental control and alternative diagnoses.
Drugs usually considered in this category include methotrexate, cyclosporin, azathioprine, 6-mercaptopurine, colchicine, intravenous gamma globulin and gold salts. Studies using these drugs have been small in number and have had variable results. More information is available for methotrexate and cyclosporine than for others. Most studies have been performed in adults, although two small series have looked at children or adolescents.

\section{Recommendations:}

i) These potentially toxic drugs should be reserved for subjects with severe asthma dependent on long term oral corticosteroids [Level 3A].

ii) Because of the nature of the clinical problems associated with severe steroid dependent asthmatics who may require further intervention, these patients should be referred to a specialized centre for management and planning [Level 3A].

Immunotherapy: This consists of the administration by subcutaneous injection of graded doses of allergenic abstracts. It has been used in the treatment of allergic disease for many decades. Its limited efficacy in asthma as opposed to allergic rhinitis has been recognized for many years.

\section{Recommendations:}

i) Immunotherapy is generally not recommended in the management of asthma [Level 1D].

ii) Immunotherapy for multiple antigens is not recommended [Level 3D].

iii) At present, immunotherapy with certain single clinically relevant allergens may be considered if disease activity is inadequately controlled by allergen avoidance and pharmacological therapy [Level 1B].

iv) Issues of safety, cost and efficacy should be considered before any decision to initiate such therapy [Level 3D].

v) Immunotherapy when carried out should be done in specialized centres [Level 3B].

\section{AEROSOL DEVICES FOR ASTHMA}

The success of aerosol drug therapy for asthma requires that the patient master a complex technique to inhale the drug deeply into the airways. Improper technique is common and as many as $50 \%$ of patients with asthma experience problems as a result. Since each aerosol delivery device has different deposition characteristics, it cannot be assumed that the therapeutic and side effect profiles will be the same following the change from one device to another.

\section{Recommendations - delivery devices for asthma:}

i) Aerosol drug delivery is recommended over oral or parenteral delivery for the same drugs [Level 1A].

ii) The aerosol device that best fits the particular needs of the individual patient should be selected [Level 3A].

iii) In general, metered-dose inhalers with spacers can be used at any age, while dry powder inhalers provide 
adequate drug delivery in most children by the age of five years [Level 2A].

iv) Early reassessment of the adequacy of the asthma control and side effects is essential whenever a change in aerosol device is made [Level 3A].

v) Repeated assessment of the adequacy of patient aerosol technique is essential [Level 3A].

vi) Home wet nebulizers to deliver asthma medications are rarely, if ever, indicated in the management of asthma in adults and older children [Level 3E].

vii) In young children, especially infants, wet nebulisation at home may be appropriate if a trial of a metered-dose inhaler attached to a spacer device with mask is not effective [Level 3B].

\section{ASTHMA IN THE ELDERLY}

Asthma may affect $5 \%$ to $8 \%$ of the population over 65 years of age. Approximately half of the elderly with asthma developed their disease earlier in life but $2 \%$ of the general elderly population will have true late-onset asthma. Asthma is often unrecognized in the elderly and the disease is thus frequently undertreated. Asthma may be triggered or aggravated by medication including the use of acetylsalicylic acid (ASA), nonsteroidal anti-inflammatory drugs or topical (ophthalmic) or systemic beta-blocker medication. A diagnosis of asthma may be readily made in those with a past or family history of the disease who have never smoked. In those without such a history, asthma may be difficult to separate from COPD. It is thus important to conduct a trial of corticosteroid therapy, ensuring that the subject has a stable $\mathrm{FEV}_{1}$ before commencing the trial, and using an increase of $\mathrm{FEV}_{1}$ of at least $20 \%$ (a minimum of $250 \mathrm{~mL}$ ) as an indication of steroid response.

Treatment of asthma in the elderly does not differ from that in younger asthmatics, although a higher proportion of elderly asthmatics are likely to require oral or inhaled corticosteroids. As with younger patients, inhaled corticosteroid therapy is preferred in the elderly. Difficulty with the use of metered-dose or dry powder inhalers can generally be overcome by education. Spacers may be used with metered-dose inhalers, and occasionally the addition of devices to assist in activation of inhalers maybe useful. Beta2-adrenoreceptor dysfunction occurs in the elderly and may be especially severe in the elderly asthmatic. Nevertheless, inhaled beta2-agonists are generally effective and well-tolerated in the elderly. Ipratropium bromide may be useful in those who cannot tolerate or who respond poorly to beta2-agonists.

It should not be forgotten that asthma may co-exist with other diseases such as heart failure, sometimes making its diagnosis and treatment more difficult. Also, compliance and comprehension of the appropriate management strategies may be more difficult in the elderly. The elderly are usually on more medication, which tends to affect compliance and give rise to a greater risk of drug interactions.

\section{PATIENT EDUCATION}

Considerable research remains to be done to determine the ideal content and methods for asthma education programs; we suggest a pragmatic guide for such programs.

\section{Recommendations:}

i) Education is an essential component of asthma management [Level 3A]. In specific settings it has been associated with reduced morbidity due to asthma (Level 1A).

ii) Goals of asthma education should be to: a) improve control of the asthma; b) reduce asthma morbidity and mortality; c) improve quality of life and ability to function; d) reduce health care costs.

iii) The education program should aim at changing behaviour and improve: a) knowledge; b) compliance with treatment; c) self-assessment abilities; d) patient-health care provider relationships.

iv) Education programs should include: a) specific information with a practical goal; b) knowledge focused on self-monitoring and self-regulation of medication; c) discussion of the two main components of asthma, inflammation and bronchoconstriction; d) measures of allergen-avoidance in sensitized patients; e) medication (bronchodilators versus anti-inflammatory agents): effects, indications, side effects; f) how and when to use preventative medications; $g$ ) proper use of aerosol delivery devices; h) how to monitor severity of asthma and change therapy with the help of an action plan; i) specific information on food allergy, sulphite or ASA intolerance; j) the hazards of smoking and other irritant exposures to be avoided; k) the role of complicating conditions such as gastroesophageal reflux and sinusitis.

v) Methods may vary and the selection of a format may change according to resources and individuals.

vi) Frequent evaluation of understanding and application of learned behaviour is necessary.

vii) Regular follow-up and communication among the health care providers involved is essential.

viii) A list of materials and resources should be given to the asthmatic patient.

\section{PATIENT ADHERENCE TO TREATMENT}

Patient compliance or adherence to therapy is defined as "the extent to which the patient's behaviour, in terms of taking medication, following diets, or executing life style changes, coincides with a clinical prescription" (Haynes RB, Taylor D, Sackett D. Compliance in Health Care. Baltimore: The Johns Hopkins University Press, 1979).

\section{Recommendations:}

i) Because of the importance of adherence to asthma management, every physician is encouraged (exhorted) to assess compliance, particularly in patients who fail to respond to usual treatment or who identify themselves as being at high risk for noncompliance [Level 3A].

ii) Careful nonthreatening, nonjudgemental questioning regarding adherence is recommended [Level 3A].

iii) Inhaler technique with the patient's usual device should 
be demonstrated to an expert observer periodically [Level 3B].

iv) It is recommended that, where possible, medication be administered twice a day or perhaps even once a day [Level 1A].

\section{EMERGENCY THERAPY OF THE ACUTE ATTACK}

The consensus group did not specifically address this issue because it has recently been reviewed in detail by a working group convened by the Canadian Association of Emergency Room Physicians. This consensus document has been submitted for publication. The following is a summary of its key recommendations:

\section{A. Evaluation:}

i) A structured assessment and treatment plan should be used in treating asthma in the emergency department [Level 2B].

ii) The severity of airflow obstruction should be determined objectively using pulmonary function tests [Level 1A].

\section{B. Therapy:}

i) Short-acting beta2-agonists, by the inhaled route, are first-line therapy to relieve bronchoconstriction in acute asthma [Level 1A].

ii) Beta2-agonists should be titrated to effect using objective and clinical measures of improved air flow to guide the dose or frequency of administration [Level $1 \mathrm{~A}]$.

iii) All patients treated in the emergency department for an acute exacerbation of asthma should be considered to be candidates for systemic corticosteroids [Level 1A].

iv) Oral and intravenous corticosteroids are equally effective in most asthmatic patients in emergency [Level $1 \mathrm{~A}]$.

v) Inhaled corticosteroids are an integral component of therapy and should be used, upon discharge, in all patients receiving oral prednisone [Level 1A].

C. Discharge planning and patient follow-up:

i) Consideration for discharge is based on spirometric values and assessment of clinical risk factors for relapse [Level 1A].

ii) A discharge treatment plan and clear instruction for follow-up are ideal for patients discharged from the emergency department [Level 3A].

\section{MANAGEMENT DURING HOSPITALIZATION}

Although the group did not embark on a major review of the management of acute asthma, it was felt that an area not covered by the Canadian Association of Emergency Physicians guidelines, and which was of some importance, was the in-hospital management of the nonmechanically ventilated patient.

\section{Recommendations:}

i) All hospitalized patients should be given systemic corticosteroids and, if not already prescribed, inhaled corticosteroids should be initiated while in hospital [Level 1A].

ii) Continued regular bronchodilator therapy, primarily with short-acting beta2-agonists, is recommended [Level $3 \mathrm{~A}]$.

iii) For cost effectiveness and educational reasons, use of wet nebulisation is discouraged and, at a minimum, early transition to metered-dose inhaler therapy, ideally with a spacer, should take place [Level 2A].

iv) Ongoing surveillance with daily (minimum) measurement of $\mathrm{FEV}_{1}$ or $\mathrm{PEF}$ is recommended [Level 3B].

v) Patients with severe airflow obstruction $\left(\mathrm{FEV}_{1}\right.$ less than $35 \%$ predicted or who are hypercarbic) should be closely monitored, ideally in a critical care area [Level $3 \mathrm{~A}]$.

vi) In the initial intensive phase of therapy, supplemental oxygen is recommended but should be guided by oximetry in the recovery phase. More severely obstructed patients ( $\mathrm{FEV}_{1}$ less than $35 \%$ predicted) or those who are hypercarbic at presentation will require ongoing close monitoring of arterial blood gases [Level $3 \mathrm{~A}]$.

vii) Intensive education of the patient should be carried out during the hospitalization. [Level 1A].

viii) A patient being discharged from hospital should continue on systemic prednisone for at least seven to 10 days and be referred back to his or her primary care physician for resumption of usual care. Patients with asthma of such severity will require inhaled corticosteroids on discharge and, if not available in the acute phase, a follow-up specialist referral would be deemed appropriate [Level 3A].

ix) Bronchodilator therapy will need to be modified in the discharge period, usually reverting to prn short-acting inhaled beta2-agonists [Level 3A].

\section{BIBLIOGRAPHY (by section)}

\section{PREAMBLE}

Gibson P. Asthma guidelines and evidence-based medicine. Lancet 1993;342:1305.

Naylor CD. Grey zones of clinical practice: some limits to evidence-based medicine. Lancet 1995;345:840-2.

Rosenberg W, Donald A. Evidence based medicine: an approach to clinical problem-solving. BMJ 1995;310:1122-6.

DEFINITION AND PATHOGENESIS

McFadden ER Jr, Gilbert IA. Asthma. N Engl J Med 1992;327:1928-37.

O'Byrne PM. Airway inflammation and the pathogenesis of asthma. Can Respir J 1994;1:189-95.

\section{THE MANAGEMENT OF ASTHMA}

General principles:

British Thoracic Society. Guidelines for the management of asthma: a summary. BMJ 1993;306:776-82.

Hargreave FE, Dolovich J, Newhouse MT. The assessment and treatment of asthma: a conference report. J Allergy Clin Immunol 1990;85:1098-111.

International Asthma Management Project and NHLBI Institute. International consensus report on diagnosis and treatment of asthma. Eur Respir J 1992;5:601-41.

International Paediatric Asthma Consensus Group. Asthma: a follow-up statement. Arch Dis Child 1992;67:240-8.

National Asthma Education Program. Guidelines for the diagnosis and 
management of asthma. Expert Panel Report. J Allergy Clin Immunol 1991;88:425-534.

\section{Diagnosis:}

Adelroth E, Hargreave FE, Ramsdale EH. Do physicians need objective measurements to diagnose asthma? Am Rev Respir Dis 1986;134:704-7.

American Association of Allergy and Immunology. Skin testing and radioallergosorbent testing (RAST) for diagnosis of specific allergens responsible for IgE-mediated diseases. J Allergy Clin Immunol 1983;72:515-7.

American Thoracic Society. Lung function testing: selection of reference values and interpretative strategies. Am Rev Respir Dis 1991;144:1202-18

Clarke JR, Reese A, Silverman M. Bronchial responsiveness and lung function in infants with lower respiratory tract illness over the first six months of life. Arch Dis Child 1992;67:1454-8.

Duff AL, Pomeranz ES, Gelber LE, et al. Risk factors for acute wheezing in infants and children: viruses, passive smoke and $\mathrm{IgE}$ antibodies to inhalant allergens. Pediatrics 1993;92:535-40.

Juniper EF, Cockcroft DW, Hargreave SE. Histamine and methacholine inhalation tests: a laboratory tidal breathing protocol, 2nd edn. Lund: Astra DrayCo AB, 1994

Morgan WJ, Martinez FD. Risk factors for developing wheezing and asthma in childhood. Pediatr Clin North Am 1992;39:1185-203.

Silverman M. Out of the mouths of babes and sucklings: lessons from early childhood asthma. Thorax 1993;48:1200-4.

Sporik R, Holgate ST, Cogswell JJ. Natural history of asthma in childhood - a birth cohort study. Arch Dis Child 1991;66:1050-3.

\section{Patient monitoring:}

Epstein SW, Manning CP, Ashley MJ, Corey PN. Survey of the clinical use of pressurized aerosol inhalers. Can Med Assoc J 1979;120:813-24.

Charlton I, Charlton G, Broomfield J, Mullee MA. Evaluation of peak flow and symptoms only self management plans for control of asthma in general practice. BMJ 1990;301:1355-9.

Hyland ME, Kenyon CA, Allen R, Howarth P. Diary keeping in asthma: comparison of written and electronic methods. BMJ 1993;306:487-9.

Kendrick AH, Higgs CM, Whitfield MJ, Laszlo G. Accuracy of perception of severity of asthma: patients treated in general practice. BMJ 1993;307:422-4.

Malo JL, L'Archevêque J, Trudeau C, D'Aquino C, Cartier A. Should we monitor peak expiratory flow rates or record symptoms with a simple diary in the management of asthma? J Allergy Clin Immunol 1993;91:702-9.

Quackenboss JJ, Lebowitz MD, Krzyzanowski M. The normal range of diurnal changes in peak expiratory flow rates. Relationship to symptoms and respiratory disease. Am Rev Respir Dis 1991;143:323-30.

Gautrin D, D’Aquino LC, Gagnon G, Malo JL, Cartier A. Comparison between peak expiratory flow rates (PEFR) and $\mathrm{FEV}_{1}$ in the monitoring of asthmatic subjects at the outpatient clinic. Chest 1994;106:1419-26.

\section{ENVIRONMENTAL ISSUES}

\section{Respiratory irritants:}

Bascom R, Bromberg PA, Costa DA, et al. Health effects of outdoor air pollution (Part 1). Am J Respir Crit Care Med 1996;153:3-55.

Chilmonczyk BA, Salmun LM, Megathlin KN, et al. Association between exposure to environmental tobacco smoke and exacerbations of asthma in children. N Engl J Med 1993;328:1665-9.

Infante-Rivard C. Childhood asthma and indoor environmental risk factors. Am J Epidemiol 1993;137:834-44.

Molfino NA, Wright SC, Katz I, et al. Effect of low concentrations of ozone on inhaled allergen responses in asthmatic subjects. Lancet 1991;338:199-203.

Murray AB, Morrison BJ. Passive smoking and the seasonal difference of severity of asthma in children. Chest 1988;94:701-8.

Reisman RE, Mauriello PM, Davis GB, Georgitis JW, DeMasi JM. A double-blind study of the effectiveness of a high-efficiency particulate air (HEPA) filter in the treatment of patients with perennia allergic rhinitis and asthma. J Allergy Clin Immunol 1990;85:1050-7.

\section{Aero-allergens:}

Chan-Yeung M, Quirce S. Aeroallergens and asthma. Can Respir J 1994; $1: 248-56$

Murray AB, Ferguson AC. Dust free bedrooms in the treatment of asthmatic children with house dust mite allergy; a controlled trial. Pediatrics 1983;71:418-22.

Henderson FW, Henry MM, Ivins SS, et al. Correlates of recurrent wheezing in school-age children. Am J Respir Crit Care Med 1995; 151:1786-93

O'Hollaren MT, Yunginger JW, Offord KP, et al. Exposure to an aeroallergen as a possible precipitating factor in respiratory arrest in young patients with asthma. N Engl J Med 1991;324:359-63.

Sporik R, Holgate ST, Platts-Mills TAE, Cogswell JJ. Exposure to house-dust mite allergen (Der $p$ I) and the development of asthma in childhood: A prospective study. N Engl J Med 1990;323:502-7.

Targonski PV, Persky VW, Ramekrishnan V. Effect of environmental molds on risk of death from asthma during the pollen season. J Allergy Clin Immunol 1995;95:955-61.

\section{Occupational asthma:}

Canadian Thoracic Society. Occupational asthma: recommendations for diagnosis, management and assessment of impairment. Can Med Assoc J 1989;140:1029-32.

Cartier A, Bernstein IL, Burge PS, et al. Guidelines for bronchoprovocation on the investigation of occupational asthma. J Allergy Clin Immunol 1989;84:823-9.

Chan -Yeung M, Malo J-L. Natural history of occupational asthma. In: Bernstein IL, Chan-Yeung M, Malo JL, Bernstein DI, eds. Asthma in the workplace. New York: Marcel Dekker, Inc, 1993:299-322.

Malo JL, Ghezzo H, L'Archeveque J, Lagier F, Perrin B, Cartier A. Is the clinical history a satisfactory means of diagnosing occupational asthma? Am Rev Respir Dis 1991;143:528-32.

Viral Infections:

Busse W, Castleman W. Early childhood asthma: what are the questions? Infections. Am J Respir Crit Care Med 1995;151:S20-2.

Martinez FD, Wright AL, Taussig LM, Holberg CJ, Halonen M, Morgan WJ. Asthma and wheezing in the first six years of life. N Engl J Med 1995;332:133-8

\section{DRUG THERAPY OF ASTHMA}

Inhaled corticosteroids:

Barnes PJ. Drug therapy: inhaled glucocorticoids for asthma. N Engl J Med 1995:332:868-75.

British Thoracic Society (BTS). Guidelines on the management of asthma. Thorax 1993;48(Suppl):S1-24.

Ernst P, Spitzer WO, Suissa S, et al. Risk of fatal and near-fatal asthma in relation to inhaled corticosteroid use. JAMA 1992;268:3462-4.

Haahtela T, Jarvinen M, Kava T. Comparison of a $\beta$-2-agonist, terbutaline, with an inhaled corticosteroid, budesonide, in newly detected asthma. N Engl J Med 1991;325:388-92.

Juniper EF, Kline PA, Vanzieleghem MA, Ramsdale EH, O’Byrne PM, Hargreave FE. Effect of long-term treatment with an inhaled corticosteroid (budesonide) on airway hyper-responsiveness and clinical asthma in nonsteroid-dependent asthmatics. Am Rev Respir Dis 1990;142:832-6.

Larsen GL. Asthma in children. N Engl J Med 1992;326:1540-5.

Meltzer EO, Orgel HA, Ellis EF, Eigen HN, Hemstreet MP. Long-term comparison of three combinations of albuterol, theophylline, and beclomethasone in children with chronic asthma. J Allergy Clin Immunol 1992;90:2-11.

O’Driscoll BR, Kalra S, Wilson M, Pickering CAC, Carroll KB, Woodcock AA. Double-blind trial of steroid tapering in acute asthma. Lancet 1993;341:324-7.

Selroos O, Pietinalho A, Löfroos A-B, Riska H. Effect of early vs late intervention with inhaled corticosteroids in asthma. Chest 1995;108:1228-34.

Van Essen-Zandvliet EE, Hughes MD, Waalkens HJ, Duiverman EJ, Pocock SJ, Kerrebijn KF. Effects of 22 months of treatment with inhaled corticosteroids and/or beta-2-agonists on lung function, airway responsiveness, and symptoms in children with asthma. Am Rev Respir Dis 1992;146:547-54.

\section{Safety of inhaled corticosteroids:}

Konig P, Hillman L, Cervantes C, et al. Bone metabolism in children with asthma treated with inhaled beclomethasone dipropionate. J Pediatr 1993;122:219-26.

Merkus PJ, van Essen-Zandvliet EE, Duiverman EJ, van Houwelingen HC, Kerrebijn KF, Quanjer PH. Long-term effect of inhaled corticosteroids on growth rate in adolescents with asthma. Pediatrics 1993;91:1121-6.

Pedersen S. Safety aspects of corticosteroids in children. Eur Respir Rev 1994;4:33-43.

Simons FE, Persaud MP, Gillespie CA, Cheang M. Shuckett EP. Absence of posterior subcapsular cataracts in young patients treated with inhaled glucocorticoids. Lancet 1993;342:776-8. 
Toogood JH. Complications of topical steroid therapy for asthma. Am Rev Respir Dis 1990;141:S89-96.

Volovitz B, Amir J, Malik H, Kauschansky A, Varsano I. Growth and pituitary-adrenal function in children with severe asthma treated with inhaled budesonide. N Engl J Med 1993;329:1703-8.

\section{Anti-allergic agents:}

Francis RS, McEnery G. Disodium cromoglycate compared with beclomethasone dipropionate in juvenile asthma. Clin Allergy 1984;14:537-40.

Rebuck AS, Kesten S, Boulet LP, et al. A 3-month evaluation of the efficacy of nedocromil sodium in asthma: a randomized double-blind, placebo-controlled trial of nedocromil sodium conducted by a Canadian multicenter study group. J Allergy Clin Immunol 1990;85:612-7.

Shapiro GG, Sharpe M, De Rouen TA, et al. Cromolyn versus triamcinolone acetonide for youngsters with moderate asthma. J Allergy Clin Immunol 1991;88:742-8.

Svendsen UG, Jorgensen $\mathrm{H}$. Inhaled nedocromil sodium as additional treatment to high dose inhaled corticosteroids in the management of bronchial asthma. Eur Respir J 1991;4:992-9.

Van Asperen PP, McKay KO, Mellis CM, et al. A multicentre randomised placebo controlled double blind study on the efficacy of ketotifen in infants with chronic cough or wheeze. J Paediatr Child Health 1992;28:4442-6.

Wong CS, Cooper S, Britton JR, Tattersfield AE. Steroid sparing effect of nedocromil sodium in asthmatic patients on high doses of inhaled steroids. Clin Exp Allergy 1993;23:370-6.

Short acting beta2-agonists:

Cockcroft DW, McParland CP, Britto SA, Swystun VA, Rutherford BC. Regular inhaled salbutamol and airway responsiveness to allergen. Lancet 1993;342:833-7.

Lipworth BJ. Risks versus benefits of inhaled $\beta_{2}$-agonists in the management of asthma. Drug Safety 1992;7:54-70.

Sears MR, Taylor DR, Print CG, et al. Regular inhaled beta-agonist treatment in bronchial asthma. Lancet 1990;336:1391-6.

Suissa S, Ernst P, Boivin J-F, et al. A cohort analysis of excess mortality in asthma and the use of inhaled beta-agonists. Am J Respir Crit Care Med 1994;149:604-10.

\section{Long acting beta2-agonists:}

Boulet LP. Long- versus short-acting $\beta_{2}$-agonists: implications for drug therapy. Drugs 1994;47:207-22.

Greening AP, Ind PW, Northfield M, Shaw G. Added salmeterol versus higher-dose corticosteroid in asthma patients with symptoms on existing inhaled corticosteroid. Lancet 1994;344:219-24.

Woolcock AJ, Lundback B, Ringdal N, Jacques LA. Comparison of addition of salmeterol to inhaled steroids with doubling the dose of inhaled steroids Am J Resp Crit Care Med. (In press)

\section{Theophylline and its derivatives:}

Barnes PJ, Pauwels RA. Theophylline in the management of asthma: time for reappraisal? Eur Respir J 1994;7:579-91.

Furukawa CT, Shapiro GG, Bierman CW, et al. A double-blind study comparing the effectiveness of cromolyn sodium and sustained-release theophylline in childhood asthma. Pediatrics 1984;74:453-9.

Hendeles L, Weinberger M. Theophylline: a "state of the art" review. Pharmacotherapy 1983;3:2-44.

Rivington RN, Boulet LP, Côté J, et al. Efficacy of Uniphyl, salbutamol, and their combination in asthmatic patients on high-dose inhaled steroids. Am J Respir Crit Care Med 1995;151:325-32.

Sessler CN. Theophylline toxicity: clinical features of 116 consecutive cases. Am J Med 1990;88:567-76.

\section{Anticholinergics:}

Gross NJ, Skorodin MS. Role of the parasympathetic system in airway obstruction due to emphysema. N Engl J Med 1984;311:421-5.

Rebuck AS, Gent M, Chapman KR. Anticholinergic and sympathomimetic combination therapy of asthma. J Allergy Clin Immunol 1983;71:317-23.

Nonsteroidal immunosuppressive therapy:

Alexander AG, Barnes NC, Kay AB. Trial of cyclosporin in corticosteroiddependent chronic severe asthma. Lancet 1992;339:324-8.

Nierop G, Gijzel WP, Bell EH, et al. Auranofin in the treatment of steroid dependent asthma: a double blind study. Thorax 1992;47:349-54.

Stewart GE, Diaz JD, Lockey RF, et al. Comparison of oral pulse methotrexate with placebo in the treatment of severe glucocorticosteroiddependent asthma. J Allergy Clin Immunol 1994;94:482-9.
Immunotherapy:

Bousquet J, Hejjaoui A, Michel FB. Specific immunotherapy in asthma. J Allergy Clin Immunol 1990;86:292-305.

\section{AEROSOL DEVICES FOR ASTHMA}

Boulet LP, d'Amours P, Bérubé D, Rouleau M, Parent JG, Pelletier C, Touchette C. Mise a jour sur l'inhalothérapie dans l'asthme et les bronchopathies obstructives chroniques. Union Med Can 1994:123:23-31.

Newhouse MT, Dolovich MB. Control of asthma by aerosols. N Engl J Med 1986;315:870-4.

Newhouse MT. Are nebulizers obsolete for administering asthma medications to infants and children? Pediatr Pulmonol 1993;15:271-2

Pedersen S. Inhalers and nebulizers: which to choose and why. Respir Med 1996;90:69-77.

\section{PATIENT EDUCATION}

Boulet LP, Chapman KR, Green LW, Fitzgerald JM. Asthma education. Chest 1994;106(Suppl):184S-96S

\section{PATIENT ADHERENCE TO TREATMENT}

Eisen S, Miller DK, Woodward RS, Spitznagel E, Przybeck R. The effect of prescribed daily dose frequency on patient medication compliance. Arch Intern Med 1990;150:1881-4.

\section{LIST OF PARTICIPANTS}

Allan B Becker, Winnipeg, Manitoba; Denis Bérubé, Montreal, Quebec; Robert C Beveridge, Saint John, New Brunswick; Louis-Philippe Boulet, Sainte-Foy, Quebec; Dennis M Bowie, Halifax, Nova Scotia; Gerry Canny, Toronto, Ontario; André Cartier, Montreal, Quebec; Andrew Cave, Edmonton, Alberta; Kenneth R Chapman, Toronto, Ontario; Victor Chernick, Winnipeg, Manitoba; Donald W Cockcroft, Saskatoon, Saskatchewan; Robert L Cowie, Calgary, Alberta; Mervyn Dean, Corner Brook, Newfoundland; Jerry Dolovich, Hamilton, Ontario; Pierre Ernst, Montreal, Quebec; Alexander Ferguson, Vancouver, British Columbia; J Mark FitzGerald, Vancouver, British Columbia; Anton Grunfeld, Vancouver, British Columbia; Frederick E Hargreave, Hamilton, Ontario; Frank A Herbert, Edmonton, Alberta; Richard Hodder, Ottawa, Ontario; Robert H Hyland, Toronto, Ontario; Dan Hughes, Halifax, Nova Scotia; Ian MacLusky, Toronto, Ontario; Bruce Mazer, Montreal, Quebec; William Moot, London, Ontario; Cheri Nijssen-Jordan, Calgary, Alberta; Paul O’Byrne, Hamilton, Ontario; Grahame Owen, Oakville, Ontario; Sharon Peters, St John's, Newfoundland; Georges Rivard, Sainte-Foy, Quebec; Robert N Rivington, Ottawa, Ontario; Paul Roumeliotis, Montreal, Quebec; Robert Schellenberg, Vancouver, British Columbia; Malcolm R Sears, Hamilton, Ontario; Sheldon Spier, Calgary, Alberta; Robert L Thivierge, Montreal, Quebec; John H Toogood, London, Ontario; Sverre Vedal, Vancouver, British Columbia; Barry Zimmerman, Toronto, Ontario; Peter C Zuberbuhler, Edmonton, Alberta

\section{SPONSORING ORGANIZATIONS}

Canadian Association of Emergency Physicians

Canadian Paediatric Society

Canadian Society of Allergy and Clinical Immunology

Canadian Thoracic Society

College of Family Physicians of Canada

Family Physician Asthma Group of Canada

The development of the present statement was made possible by the generous support of the following Canadian pharmaceutical companies: Astra Pharma Inc, Boehringer Ingelheim (Canada) Ltd, Fisons Corporation Ltd, Glaxo Wellcome Inc, Merck Frosst Canada Inc, Purdue Frederick Inc and Zeneca Pharma Inc for both the adult and pediatric working groups and Sandoz. Canada Inc for the pediatric group. 
Mellins RB, Evans D, Zimmerman B, Clark NM. Patient compliance: are we wasting our time and don't know it? Am Rev Respir Dis 1992;146:1376-7.

Pedersen S. Ensuring compliance in children. Eur Respir J 1992;5:143-5.

Rand CS, Wise RA. Measuring adherence to asthma medication regimens. Am J Respir Crit Care Med 1994;149:S69-76.

\section{EMERGENCY THERAPY OF THE ACUTE ATTACK}

Acute therapy of asthma:

Fitzgerald JM, Hargreave, FE. Acute asthma: emergency department management and prospective evaluation of outcome. Can Med Assoc J $1990 ; 142: 591-5$ 


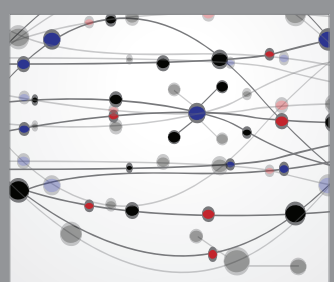

The Scientific World Journal
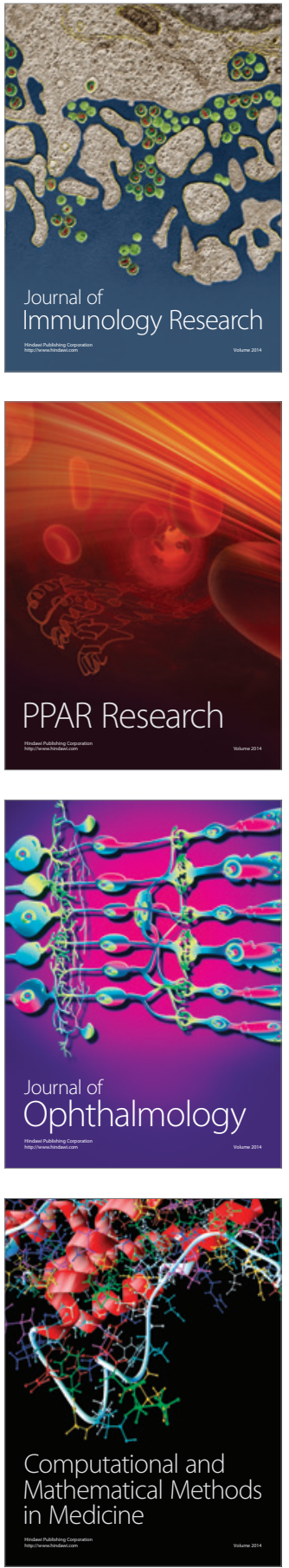

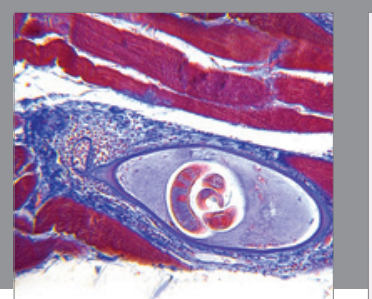

Gastroenterology Research and Practice

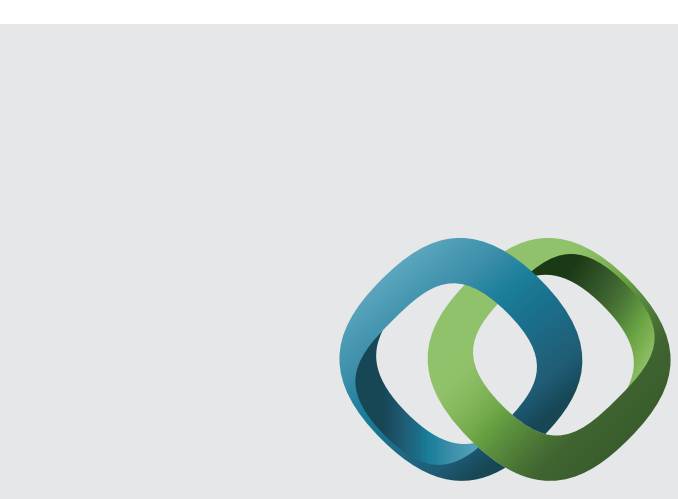

\section{Hindawi}

Submit your manuscripts at

http://www.hindawi.com
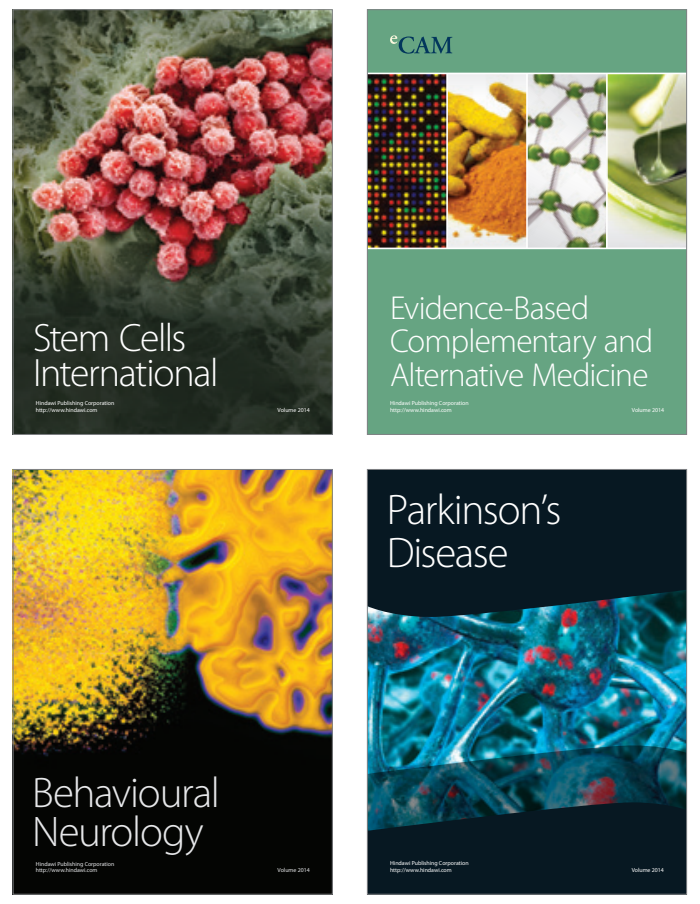
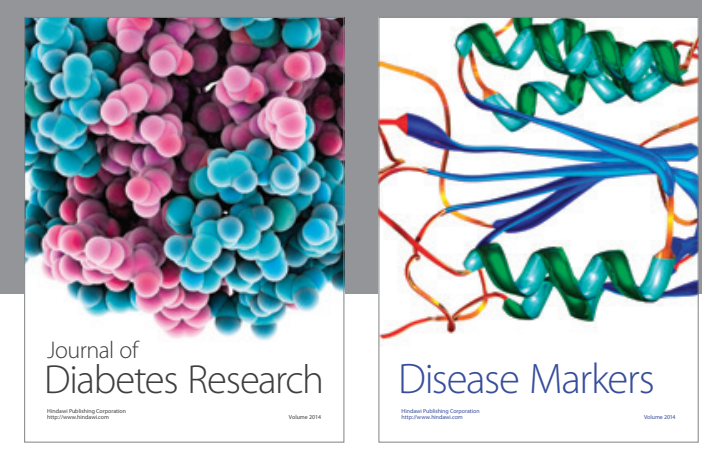

Disease Markers
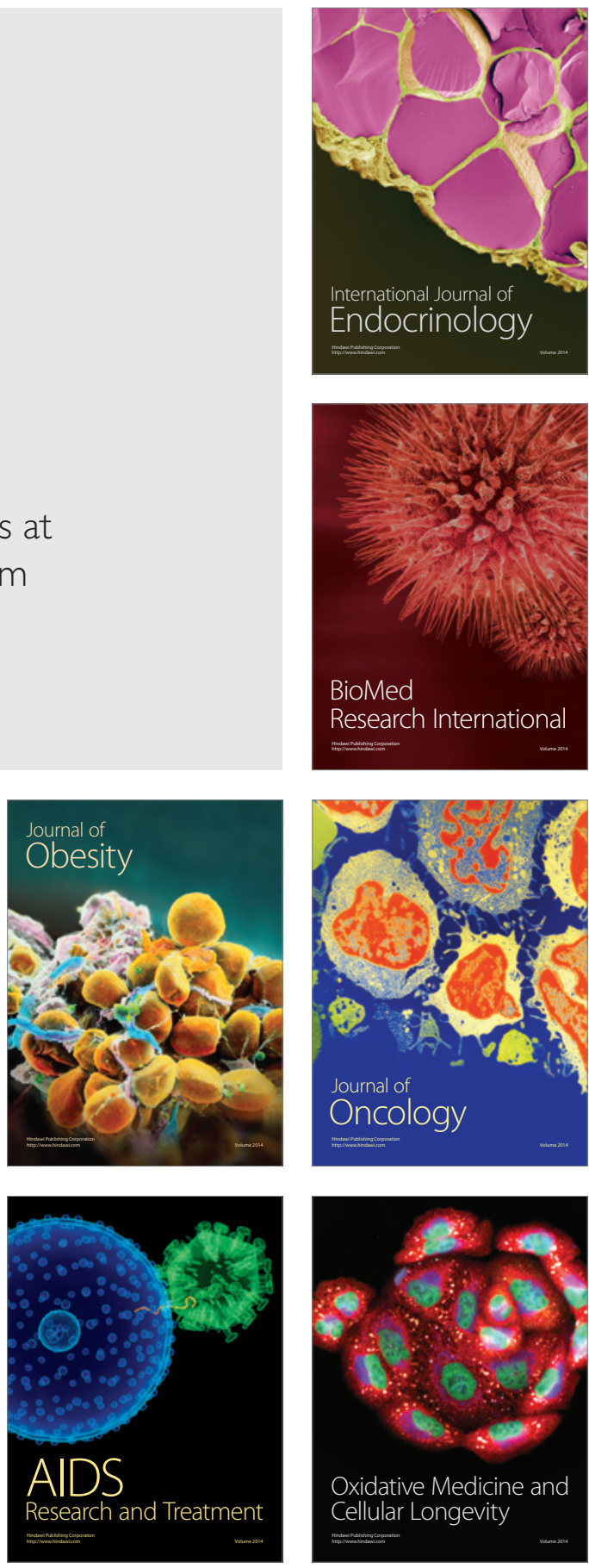